Article

\title{
Co-Culture of Filamentous Feed-Grade Fungi and Microalgae as an Alternative to Increase Feeding Value of Ethanol Coproducts
}

\author{
Cristiano E. Rodrigues Reis ${ }^{1,2}$, Larissa Ogero $D^{\prime}$ Otaviano ${ }^{1,2}$, Aravindan Rajendran ${ }^{1}$ and \\ Bo $\mathrm{Hu}^{1, *(\mathbb{D})}$ \\ 1 Department of Bioproducts and Biosystems Engineering, University of Minnesota, Minneapolis, MN 55455, \\ USA; cristianoreis@usp.br (C.E.R.R.); larissa.od@alunos.eel.usp.br (L.O.D.); arajendr@umn.edu (A.R.) \\ 2 Department of Chemical Engineering, Engineering School of Lorena, University of São Paulo, \\ São Paulo 12602-810, Brazil \\ * Correspondence: bhu@umn.edu; Tel.: +1-612-625-4215
}

Received: 24 September 2018; Accepted: 9 October 2018; Published: 11 October 2018

\begin{abstract}
Distiller's grains, an important commodity in the feed and food chains, are currently underdosed in rations due to several factors, mainly nutrient imbalance. This study aimed to increase the linoleic acid content in distiller's grains and decrease the excess nutrients in stillage water by the use of an artificial lichen, composed of fungi, algae, and a supporting matrix. A maximum concentration of $46.25 \%$ of linoleic acid in distiller's grains was achieved with a combination of Mucor indicus and Chlorella vulgaris using corn-to-ethanol whole stillage as substrate. Microbial hydrolytic enzymes during fermentation were able to decrease the solids in whole stillage. Nitrogen depletion by microalgal uptake causes lipid-formation stress to Mucor indicus cells, increasing linoleic acid production to about $49 \%$ of the total lipids, potentially decreasing costs in the animal feed. The culture supernatant can potentially be recycled as process water to the ethanol fermentation tank, and enhanced distiller's grains can replace animal-specific diets. This would reduce exogenous enzyme use and supplementation of unsaturated fatty acids from other sources.
\end{abstract}

Keywords: Chlorella vulgaris; distiller's grains; lichen; Mucor indicus; Taguchi

\section{Introduction}

Microbial communities exist as a complex and dynamically changing consortium, in which metabolic interactions between microbial species take place. The synergy between microbial communities often involves exchange of molecules for nutritional purposes, and may benefit one or both species, in a phenomenon named symbiosis. Fungi exhibit symbiotic relationships with other microbial species, and they play a vital role in ecosystem function and the maintenance of biodiversity. Lichens are ubiquitous in nature and are a synergistic collaboration between photoautotrophic algae, which convert $\mathrm{CO}_{2}$ to sugar, and release oxygen gas during photosynthesis to fungi which in turn consume sugar and oxygen then release $\mathrm{CO}_{2}$ to algae [1]. The mycoalgae (a combination of myco-from the Greek word mukēs: fungi + algae) platform developed in this study can be applied to biosystems in which fungi and algae are used industrially. The artificial lichen or mycoalgal biofilm is a novel platform technology that can be applied to many systems, mostly those which are regulated by phosphorus and nitrogen in aqueous systems [2].

The production of corn ethanol utilizes only the starch present in the kernel, leaving protein, fat, and fibers as residuals in the fermentation process, which are combined and dried to produce distiller's grains [3]. Distiller's grains are produced using the residues of the fermentation material that is processed into grain-to-ethanol fermentation facilities, briefly described in Figure 1a. Distiller's grains 
are commonly used as a protein and energy source in animal feed, despite showing limitations caused by the presence of inferior protein quality and also by the presence of non-digestible fibers, which represent zero gain in energy to animals. In addition to these, distiller's grains have animal-specific challenges, e.g., for dairy cattle a lack of linoleic acid, a key fatty acid regulating milk fat [4], is observed, while for monogastric animals, proteins and phosphorus have limited digestibility [5]. Specifically for monogastrics, a concern in distiller's grains use is the presence of non-starch polysaccharides (NSPs). NSPs are not easily degraded by monogastric animals and represent zero gain in energy or protein for this market. Many solutions have been proposed to increase digestibility of NSPs in distiller's grains, including chemical and enzymatic treatments, which are either nonselective or expensive, respectively. Nonetheless, the use of distiller's grains in animal feed formulation has been a factor in the success of dry-grind corn-to-ethanol plants over the past 20 years, with annual production capacity in the order of 40 metric tons a year [6]. A few key issues still stand out as challenges for the ethanol industry, including water usage and recyclability, and higher displacement of distiller's grains in animal feed rations. Anaerobic digestion of stillage water is currently used to decrease nutrient complexity, providing an alternative for water recycling in ethanol plants, achieving commercial rates of up to $58 \%$, though encountering technical difficulties due to the high presence of suspended solids, and imbalance of $\mathrm{C}: \mathrm{N}$, often requiring higher processing times, and not being a practice exploited to its full potential [6].

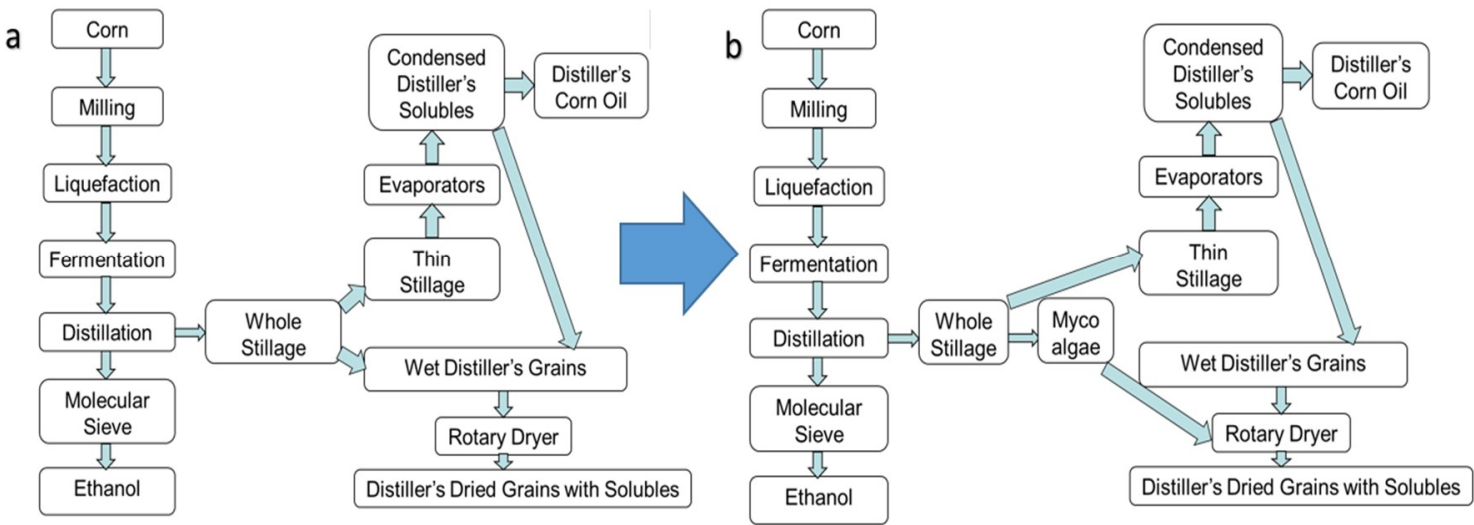

Figure 1. (a) Simplified dry-grind corn-to-ethanol processing and production of coproducts (b) Proposed process modifications using the Mycoalgae biofilm platform with whole stillage as substrate.

The use of secondary fermentation, i.e., the utilization of the fermented residues of ethanol co-products as a substrate for other microbial-based processes has been reported as a way to produce malic acid [7], ethanol [8], and a significant number of chemicals [6]. Few studies, however, focus on improving the animal feed quality by fermentation. The purpose of the current article is to present a bioprocess platform developed using whole stillage, the bottom fraction of ethanol distillation, rectifying, and stripping operations. The use of an artificial lichen biofilm, mycoalgae, composed by fungi, algae, and a supporting matrix was chosen due to the potential of algae and fungi to uptake nutrients [9] and produce hydrolytic enzymes [10], as a way to replace costly anaerobic digestion practices, and evaporation of stillage water. Simultaneously, nutrients from whole stillage are processed into the mycoalgae biomass, providing an increase in lipids and production of linoleic acid, as depicted in Figure $1 b$.

\section{Materials and Methods}

\subsection{Microorganisms, Medium Preparation, and Experimental Design}

Chlorella vulgaris 2714 (UTEX) and Mucor indicus (ATCC) were chosen as model biofilm-forming strains, and were maintained in medium A [11]. The composition of medium A contains 
(in g. $\mathrm{L}^{-1}$ ): Glucose 2, $\mathrm{KNO}_{3} 1, \mathrm{KH}_{2} \mathrm{PO}_{4} 0.075, \mathrm{~K}_{2} \mathrm{HPO}_{4} 0.1, \mathrm{MgSO}_{4} \cdot 2 \mathrm{H}_{2} \mathrm{O} 0.5, \mathrm{Ca}\left(\mathrm{NO}_{3}\right)_{2} \cdot 4 \mathrm{H}_{2} \mathrm{O}$ $0.0625, \mathrm{FeSO}_{4} \cdot 7 \mathrm{H}_{2} \mathrm{O}$ 0.01, Yeast extract 0.5. A trace metal solution was added to medium $\mathrm{A}$ at a volume of $1 \mathrm{~mL} \cdot \mathrm{L}^{-1}$. The trace metal solution contained (in $\mathrm{g} \cdot \mathrm{L}^{-1}$ ): $\mathrm{H}_{3} \mathrm{BO}_{3} 2.86, \mathrm{Na}_{2} \mathrm{MoO}_{4} \cdot 2 \mathrm{H}_{2} \mathrm{O}$ $0.39, \mathrm{ZnSO}_{4} \cdot 7 \mathrm{H}_{2} \mathrm{O} 0.22, \mathrm{MnCl}_{2} \cdot 4 \mathrm{H}_{2} \mathrm{O} 1.81, \mathrm{CuSO}_{4} \cdot 5 \mathrm{H}_{2} \mathrm{O} 0.079$, and $\mathrm{Co}\left(\mathrm{NO}_{3}\right)_{2} \cdot 6 \mathrm{H}_{2} \mathrm{O} 0.049$. The algae stock cultures were maintained in agar modified with Media A at room temperature of $25-27^{\circ} \mathrm{C}$ using artificial fluorescent light illumination at approximately $100 \mu \mathrm{mol} \mathrm{m}{ }^{-2} \cdot \mathrm{s}^{-1}$. The fungal spores used in this work were maintained in glycerol stock $(60 \%)$ at $-80{ }^{\circ} \mathrm{C}$. The glycerol stocks were streaked onto potato-dextrose agar plates and maintained in an incubator at $37^{\circ} \mathrm{C}$. The fungal spore suspension was prepared using sterile distilled water and stored at $4{ }^{\circ} \mathrm{C}$ prior to inoculation. The cell count of algae and fungal spores was performed using a Neubauer haemocytometer chamber $(0.1 \mathrm{~mm}$-depth with an area of $0.0025 \mathrm{~mm}^{2}$ ) using a National DC5-163 light microscope using $40 \times$ magnification.

Experiments were carried out in 250-mL Erlenmeyer flasks with $100 \mathrm{~mL}$ of whole stillage (WS) as culture medium. A supporting matrix of $16 \mathrm{~cm}^{2}$-polypropylene-yarn mesh was used for biofilm immobilization. The medium $\mathrm{pH}$ was adjusted using $\mathrm{HCl}\left(2 \mathrm{~mol} \cdot \mathrm{L}^{-1}\right)$ or $\mathrm{NaOH}\left(1 \mathrm{~mol} \cdot \mathrm{L}^{-1}\right) \mathrm{using}$ a laboratory-grade pH meter (Oakton, SN 153,400, Kuala Lumpur, Malaysia). Media were heat sterilized $\left(250{ }^{\circ} \mathrm{F}, 15\right.$ psi for $\left.20 \mathrm{~min}\right)$ along with the matrix. The culture medium was inoculated with the co-cultures of fungal spores and algae cells at varying ratios with the initial algal cell count fixed at $2.50 \times 10^{9}$ cells and incubated in an orbital shaker at $150 \mathrm{rpm}$ and $26^{\circ} \mathrm{C}$ in the presence of light (light intensity of continuous illumination was set to $100 \mu \mathrm{mol} \mathrm{s}{ }^{-1} \cdot \mathrm{m}^{-2}$ ) for the entire cultivation period of about 8 days. Control experiments with axenic cultures were also performed under the same conditions tested for the co-culture experiments. The medium used, WS, was collected from a dry-grind ethanol plant in the state of Iowa, USA. WS samples were obtained from a single batch and stored at $-20^{\circ} \mathrm{C}$ prior to use, and were used for medium prepared without solid-liquid separation or dilution.

Two major sets of fermentation experiments were performed in the current study: a kinetic study, with the control conditions above, an initial fungal spore:microalgae cell ratio of 1:300, and periodic samples; and a Taguchi L9 array, evaluating initial $\mathrm{pH}$, temperature, and algae:fungi inoculation ratio, each in 3 levels. These three factors were used as they are known to influence the intended effects of this study. Each condition was performed with triplicates for mycoalgae and 1 blank flask. Statistical analysis was performed using Minitab ${ }^{\circledR} 17$. The total growth time for both experiments carried out was 8 days. The L9 parametric study followed the design described in Table 1.

Table 1. Taguchi L9 Experimental Matrix.

\begin{tabular}{cccc}
\hline Experiment & $\mathbf{p H}_{\mathbf{0}}$ & Temperature $\left({ }^{\circ} \mathbf{C}\right)$ & Fungi/Algae \\
\hline 1 & 4.6 & 27 & $1 / 1200$ \\
2 & 4.6 & 30 & $1 / 600$ \\
3 & 4.6 & 33 & $1 / 300$ \\
4 & 5.7 & 27 & $1 / 600$ \\
5 & 5.7 & 30 & $1 / 300$ \\
6 & 5.7 & 33 & $1 / 1200$ \\
7 & 6.8 & 27 & $1 / 300$ \\
8 & 6.8 & 30 & $1 / 1200$ \\
9 & 6.8 & 33 & $1 / 600$ \\
\hline
\end{tabular}

\subsection{Cell Harvest and Analytical Methods}

Cell separation, and all measurements regarding cell biomass were based on [11]. The biofilm formed was removed from the Erlenmeyer flasks and analyzed in regards to its biomass distribution. The total biomass present in the biofilm was estimated as Equation (1):

$$
\mathrm{B}_{\mathrm{T}}=\mathrm{B}_{\mathrm{F}}+\mathrm{B}_{\mathrm{A}}+\mathrm{S}_{\mathrm{WS}}
$$


where all the units are in $\mathrm{g}$, and $\mathrm{B}_{\mathrm{T}}$ accounts for the total biomass in the biofilm, $\mathrm{B}_{\mathrm{F}}$ is the fungal biomass, $\mathrm{B}_{\mathrm{A}}$ is the microalgal biomass, and $\mathrm{S}_{\mathrm{WS}}$ is the weight of the WS solids present in the biofilm matrix. After the completion of biofilm formation, samples of the formed biofilm were taken in order to determine the moisture content via classical gravimetry. $\mathrm{B}_{\mathrm{T}}$ was then determined as the dry weight after the completion of biofilm formation. Samples of the wet biofilm were taken to determine $B_{F}$ and $\mathrm{B}_{\mathrm{A}}$ via indirect measurements. $\mathrm{S}_{\mathrm{WS}}$ was calculated as $\mathrm{B}_{\mathrm{T}}$ minus $\mathrm{B}_{\mathrm{F}}$ and $\mathrm{B}_{\mathrm{A}}$. $\mathrm{B}_{\mathrm{A}}$ was estimated via indirect measurement of chlorophyll-a (Chl-a) with the aid of a standard curve relating concentration of Chl-a and dry algal biomass weight. A spectrophotometer (Shimadzu UV-1800, Torrance, CA, USA) was used to read Chl-a after biomass homogenization with methanol (90 vol. \%). Algal biomass in the biofilm samples was determined indirectly by measuring chlorophyll-a (Chl-a) concentration and determining the algal biomass using a standard chart of Chl-a concentration and dry biomass. Chl-a concentration is determined spectrophotometrically (Shimadzu UV spectrophotometer, UV-1800, Torrance, CA, USA) by homogenizing and extracting the cell suspension with methanol solution $(90 \%$ $v / v$ ) with a measurement at $650 \mathrm{~nm}$ [11]. The chlorophyll-a and algal biomass was correlated using the standard Equation (2):

$$
\text { Dry Algal Biomass }(\mathrm{mg})=8.037 \times \operatorname{Abs}_{(\lambda=690 \mathrm{~nm})}\left[R^{2}=0.99\right]
$$

The fungal biomass contribution was also determined indirectly by measuring the glucosamine content in the total biomass. The amount of glucosamine is characteristic to each species and it remains constant throughout the fermentation time. Glucosamine for the species involved was determined following a methodology described by [12]. The relationship obtained is described in Equation (3).

$$
\text { Glucosamine }\left(\mathrm{mg} \cdot \mathrm{L}^{-1}\right)=11.63 \times \operatorname{Abs}_{(\lambda=530 \mathrm{~nm})}\left[\mathrm{R}^{2}=0.97\right]
$$

The fungal biomass in the biofilm was determined by the measurement of the biomass glucosamine and by the concentration ratios developed for both strains analyzed as $59.46 \mathrm{mg}$ glucosamine $\mathrm{g}^{-1} \mathrm{M}$. indicus biomass and $9.18 \mathrm{mg}$ glucosamine $\mathrm{g}^{-1} \mathrm{C}$. vulgaris biomass.

Total phosphorus (TP), total nitrogen (TN) and chemical oxygen demand (COD) in the culture liquid were measured using Hach TNTplus ${ }^{\circledR}$ analysis kits (TNT 845, TNT 827, and TNT 822, respectively). For lipid analysis, biofilm biomass samples were oven-dried until constant weight at $105{ }^{\circ} \mathrm{C}$, and processed according to the Bligh-Dyer method. Lipid content was determined by calculating the weight percentage of lipid in dry biomass, and lipid profile was measured using Gas Chromatography with a Flame Ionization Detector (GC-FID) [13].

Enzymatic activities were estimated using timed hydrolytic activities on pure standard substrates, and 1 unit (U) was defined as the amount required to generate $1 \mu \mathrm{mol}$ of substrate per minute of reaction.

\section{Results and Discussion}

\subsection{Mycoalgae Development in Whole Stillage}

Chlorella vulgaris and Mucor indicus were inoculated in Erlenmeyer flasks containing WS and the presence of an attachment matrix. Initially, the matrix biomass was composed mostly by WS solids, with little fungal biomass (Figure 2). Fungal cell growth occurred on a similar process [11], with fungal mycelia initially developing on the mesh material, with later algae attachment. Leveraging the use of WS for fermentation may positively impact the whole co-products processing, potentially decreasing dry-grind process complexity. M. indicus is generally-regarded-as-safe (GRAS) and C. vulgaris has beneficial effects if included in animal feed at optimal levels [14]. 


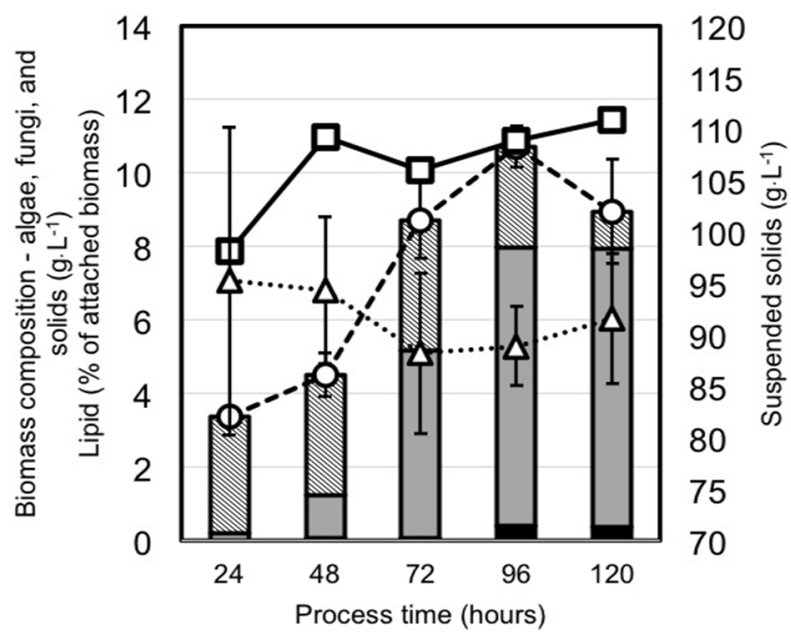

Figure 2. Kinetic profile of mycoalgae biofilm growth in in natura whole stillage. Hatched grey bars account for the total solids in biomass; dark grey bars account for fungal biomass in the biofilm; black bars account for the algal biomass in the biofilm; circles and the dashed line account for the total weight of the biofilm at a given time point following a time profile; squares represent the lipid percentage present in the biofilm at a given time point; triangles represent the measurement of total suspended solids in the culture supernatant phase (not attached to the biofilm).

\subsection{Cell Growth-Kinetics and Biomass Distribution}

The assumption used in this work was that WS was a feedstock material rich enough to sustain microbial growth, and despite having complex macromolecules, such as proteins and polysaccharides derived from corn and yeast, it could still promote a significant fungal growth given enough oxygenation, potentially increased by algae cultivation. While the total biomass present in the biofilm was the highest at around $96 \mathrm{~h}\left(10.7 \mathrm{~g} \cdot \mathrm{L}^{-1}\right)$ of the process, it decreases to $8.9 \mathrm{~g} \mathrm{~L}^{-1}$ at $120 \mathrm{~h}$. The fungal and algal components in the biomass either plateaued or grew during the entire cultivation time, indicating a loss in attached solids in the biofilm. The total attached solids in the mycoalgae biofilm decreased from $3.15 \mathrm{~g} \cdot \mathrm{L}^{-1}$ in the first day of cultivation to around $1 \mathrm{~g} \mathrm{~L}-1$ after $120 \mathrm{~h}$ of growth, possibly caused by the production of hydrolytic enzymes by the fungi and algae present in the biofilm. Results are in consonance with those presented by [9], indicating an increase in microbial biomass with concurrent decrease in the solid content as the process time increases. Compositional analysis of the biofilm indicate that the microbial biomass constitutes $6.6 \%$ of the total mass attached at $24 \mathrm{~h}$ of growth, and after $120 \mathrm{~h}$, it increases to $88.7 \%$ of the total biomass present in the biofilm comprising of algae and fungi (Figure 2).

In the WS co-culture process, algae biomass contributes to about $5 \%$ in the mature biofilm, higher than the 3\% reported on distiller's solubles [9]. The hypothesis for an increase in microalgae concentration in whole stillage is that the high turbidity of the complex medium posed difficulty for a purely photoautotrophic growth. It is thus believed that the consortium of algae and fungi hydrolyzed organic carbon sources present in the whole stillage to sustain algae growth in a heterotrophic system.

\subsection{Factorial Results}

\subsubsection{Nutrient Removal and Enzymatic Activity}

As one of the objectives of this study is to evaluate the enzyme-fortified water reusability in the ethanol industry by employing the fermentation of mycoalgae in whole stillage, the removal of nutrients from the supernatant phase is, thus, a desired outcome. The composition of WS showed a COD value of about $80.25 \mathrm{~g} \mathrm{O}_{2} \mathrm{~L}^{-1}$. Initial nitrogen concentration was of $1250 \mathrm{mg} \cdot \mathrm{L}^{-1}$, mostly composed by dissolved proteins, amino acids, and residues of ammonia from the corn-to-ethanol fermentation. Previous research indicates $C$. vulgaris as a microorganism with $\mathrm{N}$ removal potential, with kinetics of 
$\mathrm{N}$ uptake greater than those of fungal activities [9]. The presence of high levels of $\mathrm{P}$ has been a concern in ethanol co-products, especially due to its concentration in distiller's grains, which may not be fully degraded by animals. Initial concentration of total phosphorus present in the whole stillage medium was $1380 \mathrm{mg} \cdot \mathrm{L}^{-1}$, which was within the expected range based on published literature results. The $\mathrm{L} 9$ results in Table 2 indicate a maximum COD and $\mathrm{N}$ removal of about $52 \%$ and $82 \%$, respectively, by the mycoalgae biofilm. P removal on all conditions tested using the mycoalgae biofilm was greater than $50 \%$. Table 2 summarizes the factorial results obtained in the $L_{9}$ parametric study.

Table 2. Experimental results on decrease of Nitrogen $(\mathrm{N})$, Phosphorus $(\mathrm{P})$ and Chemical Oxygen Demand (COD) in the mycoalgae biofilm supernatant after $120 \mathrm{~h}$ of growth.

\begin{tabular}{|c|c|c|c|c|c|c|}
\hline Experiment & $\mathrm{TN}_{\mathrm{f}}\left(\mathrm{mg} \mathrm{L}^{-1}\right)$ & $\Delta \mathrm{N} \%$ & $\mathrm{TP}_{\mathrm{f}}\left(\mathrm{mg} \mathrm{L}^{-1}\right)$ & $\Delta \mathrm{P} \%$ & $\operatorname{COD}_{f}\left(g \cdot L^{-1}\right)$ & $\Delta \mathrm{COD} \%$ \\
\hline 1 & $823.33 \pm 77.78$ & 34.13 & $614.44 \pm 9.55$ & 55.48 & $44.93 \pm 6.76$ & 44.01 \\
\hline 2 & $473.00 \pm 116.37$ & 62.16 & $493.33 \pm 47.13$ & 64.25 & $32.15 \pm 4.19$ & 59.94 \\
\hline 3 & $482.62 \pm 15.79$ & 61.39 & $599.09 \pm 22.01$ & 56.59 & $36.89 \pm 11.14$ & 54.03 \\
\hline 4 & $525.21 \pm 71.37$ & 57.98 & $616.79 \pm 58.29$ & 55.31 & $39.03 \pm 8.52$ & 51.36 \\
\hline 5 & $371.17 \pm 41.37$ & 70.31 & $622.90 \pm 40.18$ & 54.86 & $28.55 \pm 4.53$ & 64.42 \\
\hline 6 & $166.67 \pm 38.18$ & 86.67 & $585.62 \pm 29.14$ & 57.56 & $31.49 \pm 10.96$ & 60.76 \\
\hline 7 & $194.33 \pm 61.52$ & 84.45 & $584.36 \pm 34.49$ & 57.66 & $37.17 \pm 3.14$ & 53.68 \\
\hline 8 & $261.02 \pm 4.95$ & 79.12 & $550.52 \pm 18.62$ & 60.11 & $32.27 \pm 1.76$ & 59.79 \\
\hline 9 & $111.73 \pm 69.86$ & 91.06 & $559.77 \pm 18.79$ & 59.44 & $41.61 \pm 5.40$ & 48.15 \\
\hline
\end{tabular}

$\Delta$ (factor) is the relative difference of the measured value in regards to its initial concentration $\left.\left(\Delta \mathrm{i}=\left(\mathrm{i}_{0}-\mathrm{i}_{\mathrm{f}}\right) / \mathrm{i}_{0}\right)\right)$; $\mathrm{i}_{\mathrm{f}}$ indicates the measurement of the parameter $\left(\mathrm{N}, \mathrm{P}\right.$, and COD) at the end of the fermentation time $(120 \mathrm{~h}) ; \mathrm{i}_{0}$ indicates the measurement of the aforementioned parameters at the initial time of the fermentation. TN: Total Nitrogen; TP: Total Phosphorus.

The chemical composition of stillage is a critical factor that limits the use of such substrate in anaerobic digestion for water recycling. In addition to removing nutrients, conditioning the reused water for further use in the upstream and fermentation steps is economically desirable. Aerobic fermentation can, thus, be an alternative to anaerobic digestion. Among the classes of enzymes used in the corn-to-ethanol process, starch-hydrolyzing enzymes are the key regulator in the fermentation of corn, nonetheless, current utilization of different classes of protease, phytase and fiber-degrading enzymes has been reported [6]. Therefore, the goal of recycling water within the ethanol production system, while simultaneously providing a suspension with hydrolytic enzymes, was evaluated, in order to potentially integrate downstream water to upstream processing of posterior batches. The maximum production of endoglucanase, xylanase, and cellulase was observed on the same experiment, and ranged from 30.77 to $38.69 \mathrm{U} \mathrm{mL}^{-1}$. The term "cellulase" used in this study is a general term for the activities of all the three types of hydrolytic enzymes present in the group; endoglucanases being one of them. As the activities for endoglucanases and cellulases are similar statistically, i.e., close to the standard deviation of one another, it can be understood that the biofilm produced most, if not all, cellulase enzymes as only endoglucanases.

From the factorial analysis, initial $\mathrm{pH}$ was the most significant factor, and the optimum value among those tested is the closest to neutral, $\mathrm{pH}=6.8$. Within the mesophilic range studied $\left(27-33^{\circ} \mathrm{C}\right)$, enzymatic production was robust, and indicated that temperature fluctuations under the mesophilic range will not likely impact the enzymatic production. Initial fungi:algae ratio is not significant at a $5 \%$-confidence level, however, there is a trend when increasing the algae population in the mycoalgae to produce greater amounts of cellulase, endoglucanase, and xylanase. As an example, using initial $\mathrm{pH}=6.8$, xylanase production increased from $29.40 \pm 4.18 \mathrm{U} \mathrm{mL}^{-1}$ to $38.69 \pm 5.51 \mathrm{U} \cdot \mathrm{mL}^{-1}$ when the initial algae population was 4 times greater, i.e., comparing results for 1:300 and 1:1200 inoculation ratio, respectively. A summary of the results is present in Table 3. 
Table 3. Experimental results on the enzymatic activity of the biofilm culture supernatant after $120 \mathrm{~h}$ of growth.

\begin{tabular}{cccc}
\hline Experiment & Xylanase $\left(\mathbf{U ~ m L}^{-\mathbf{1}}\right)$ & Endoglucanase $\mathbf{( U \cdot \mathbf { m L } ^ { - \mathbf { 1 } } )}$ & ${\text { Cellulase }\left(\mathbf{U ~ m L}^{-\mathbf{1}}\right)}$ \\
\hline 1 & $23.69 \pm 0.50$ & $23.23 \pm 0.14$ & $20.22 \pm 0.47$ \\
2 & $23.59 \pm 5.15$ & $23.37 \pm 0.16$ & $20.43 \pm 0.27$ \\
3 & $23.80 \pm 0.95$ & $23.80 \pm 0.49$ & $20.62 \pm 0.93$ \\
4 & $32.34 \pm 3.74$ & $25.49 \pm 1.01$ & $24.68 \pm 2.41$ \\
5 & $25.45 \pm 2.57$ & $23.55 \pm 1.44$ & $20.68 \pm 3.35$ \\
6 & $37.58 \pm 2.14$ & $29.76 \pm 1.74$ & $30.64 \pm 1.79$ \\
7 & $29.40 \pm 4.18$ & $24.77 \pm 1.88$ & $23.97 \pm 2.92$ \\
8 & $38.69 \pm 5.51$ & $31.88 \pm 3.66$ & $30.77 \pm 3.99$ \\
9 & $37.94 \pm 3.14$ & $31.16 \pm 1.26$ & $30.49 \pm 2.01$ \\
\hline
\end{tabular}

\subsubsection{Lipid Analysis}

Table 4 presents the results for the lipid content and linoleic acid percentages to the total lipids. Corn-to-ethanol units have been recovering distiller's corn oil from the liquid phase of whole stillage, i.e., thin stillage. Despite being of significant economic advantage for ethanol producers, DDGS derived from processes with extraction of distiller's corn oil is often reported to have inferior nutritional properties when compared to full-fat DDGS [6]. Several strains of Mucor spp. fungi have been reported as a lipid-producing and accumulating microorganisms [15]. It is known that fungal bodies begin accumulating lipids by the depletion of a nutrient, usually N [15] -WS has a COD:N ratio of 64.2, thus being a $\mathrm{N}$ deficient medium, with potential to be used with lipid-producing strains. A current concern in distiller's grains utilization for dairy cattle is the lack of linoleic acid. Linoleic acid deficiency has been linked as one of the most significant causes for milk fat depression, a condition in which the lipid content of milk from cattle is decreased [4]. Statistical analysis indicate the factor with the greatest significance on lipid accumulation to be the initial $\mathrm{pH}$ of the medium. Previous research prove that initial $\mathrm{pH}$ regulates lipid accumulation by fungi [16]. From a Pearson correlation between final total $\mathrm{N}$ concentration in the supernatant and lipid accumulation it is statistically proven $(p$-value $=0.017$, please see Supplementary Materials) that the increase in lipid accumulation is regulated by the final $\mathrm{N}$ concentration in the suspension phase. In regards to linoleic acid accumulation, a maximum of $46.25 \%$ was achieved, having as a factor the greatest significance of the initial $\mathrm{pH}$ of the medium. The presence of the algae in the biofilm formation increased the lipid quantity and the linoleic acid accumulation. The hypothesis behind this experimental fact is due to the high rates of $\mathrm{N}$ uptake by microalgae [9], which caused additional stress, causing the fungi to accumulate lipids.

Table 4. Experimental results on the lipid content of the mycoalgae biomass after $120 \mathrm{~h}$ of growth and the percentage of $\mathrm{C} 18: 2$ in regards to the total lipids attained in the biofilm.

\begin{tabular}{ccc}
\hline Experiment & Lipid (\%) & C18:2 (\% Lipid) \\
\hline 1 & $4.03 \pm 1.71$ & $11.78 \pm 1.04$ \\
2 & $6.38 \pm 2.62$ & $7.49 \pm 0.86$ \\
3 & $5.89 \pm 0.96$ & $7.33 \pm 3.87$ \\
4 & $9.49 \pm 0.97$ & $9.72 \pm 1.58$ \\
5 & $6.10 \pm 0.83$ & $7.46 \pm 2.60$ \\
6 & $9.33 \pm 1.97$ & $6.48 \pm 0.87$ \\
7 & $8.74 \pm 5.66$ & $38.98 \pm 0.59$ \\
8 & $12.08 \pm 1.68$ & $32.62 \pm 0.68$ \\
9 & $14.98 \pm 3.30$ & $46.25 \pm 1.65$ \\
\hline
\end{tabular}

\subsubsection{Statistical Significance and Overlook of Results}

Table 5 describes the significance of the parametric effects of the initial $\mathrm{pH}$, temperature, and initial ratio of algae cells and fungal spores in the process responses. At a significance level of $95 \%$, 
a few parameters were statistically significant, while others were not. The initial $\mathrm{pH}$ of the process posed a significant effect on the production of all cellulolytic enzymes, and on the lipid and C18:2 accumulation in the biomass. The results shown in the supplementary materials describe how the initial $\mathrm{pH}$ at each level imposes an effect on each of these factors. In regards to the temperature effect on all the response parameters, it comes to a surprise that all p-values were greater than 0.05. From this perspective, it can be seen that the range of temperatures analyzed for this study may not impact significantly any of these responses. The temperatures analyzed were close to previous determinations of optimum growth of both species involved, and these results imply that the developed process is rather robust over a range of mesophilic temperatures. On a similar sense, the effect of initial algae and fungal did not provide a significant response to any of the factors. The qualitative trends of each of these factors can be observed in the figures presented as supplementary materials.

Table 5. Factorial analysis on the parametric factors involved in the Taguchi analysis. The numbers account for the F statistics calculated from the Analysis of Variance (ANOVA) of the model (Supplementary Materials) and the number in parenthesis account for the significance of the parameter measured as $p$-value.

\begin{tabular}{|c|c|c|c|c|c|c|c|c|}
\hline Factor & Xyl. & E.G. & Cel. & Lipid & C18:2 & $\mathbf{T N}$ & TP & COD \\
\hline $\mathrm{pH}_{0}$ & $21.29(0.045)$ & $21.55(0.044)$ & $24.15(0.040)$ & $37.92(0.026)$ & $41.16(0.024)$ & $5.39(0.157)$ & $1.06(0.485)$ & $1.22(0.450)$ \\
\hline Temperature & $3.68(0.214)$ & $8.98(0.100)$ & $7.51(0.117)$ & $6.65(0.131)$ & $0.77(0.564)$ & $2.23(0.309)$ & $1.13(0.470)$ & $3.95(0.202)$ \\
\hline A:F & $8.00(0.111)$ & $11.76(0.078)$ & $11.32(0.081)$ & $10.18(0.089)$ & $0.62(0.616)$ & $0.16(0.864)$ & $0.96(0.511)$ & $0.51(0.661)$ \\
\hline
\end{tabular}

A:F: Algae:Fungi ratio; Xyl: Xylanase Activity; E.G.: Endoglucanase Activity; Cel.: Cellulase Activity; TN: Total Nitrogen; TP: Total Phosphorus.

\section{Conclusions}

While the biofilm grows, it takes up phosphorus and nitrogen compounds and converts them to protein and other cellular products. The mycoalgae platform provides not only an easy harvesting of the algae with no energy intensive process for separating the algae from the supernatant, but also key modifications to axenic fungal or algal processes. This common core can be applied to many cases in which phosphorus and nitrogen compounds are present and regulate the application of a specific feedstock. The use described herein demonstrates how the mycoalgae biofilm can regulate and provide solutions to high monetary value issues in the corn-to-ethanol industry.

Supplementary Materials: The supplementary materials are available online at http:/ /www.mdpi.com/2311$5637 / 4 / 4 / 86 /$ s1.

Author Contributions: C.E.R.R. and B.H. conceptualized the idea; C.E.R.R. and L.O.D. were responsible for performing the experiments; A.R. provided assistance in the experimental design and in the analyses carried out; B.H. is the P.I. of the project and revised the findings and the manuscript. All authors have read and approved this version of the manuscript.

Funding: The researchers were funded by Brazilian CAPES SwB program (grant number 13252/13-5), to FAPESP (Fundação de Amparo à Pesquisa do Estado de São Paulo-grant numbers 2017/12908-8 and 2016/10636-8), to University of Minnesota-MnDRIVE (GFV and UMII), and to Legislative-Citizen Commission on Minnesota Resources (LCCMR)-Environment and Natural Resources Trust Fund.

Conflicts of Interest: The authors declare no conflict of interest.

\section{References}

1. Reis, C.E.R.; Rajendran, A.; Silva, M.B.; Hu, B.; de Castro, H.F. The application of microbial consortia in a biorefinery context: Understanding the importance of artificial lichens. In Sustainable Biotechnology-Enzymatic Resources of Renewable Energy; Springer: Berlin, Germany, 2018; pp. 423-437.

2. Barnharst, T.; Rajendran, A.; Hu, B. Bioremediation of synthetic intensive aquaculture wastewater by a novel feed-grade composite biofilm. Int. Biodeterior. Biodegrad. 2018, 126, 131-142. [CrossRef]

3. Kim, Y.; Mosier, N.S.; Hendrickson, R.; Ezeji, T.; Blaschek, H.; Dien, B.; Cotta, M.; Dale, B.; Ladisch, M.R. Composition of corn dry-grind ethanol by-products: Ddgs, wet cake, and thin stillage. Bioresour. Technol. 2008, 99, 5165-5176. [CrossRef] [PubMed] 
4. Chilliard, Y.; Ferlay, A.; Mansbridge, R.M.; Doreau, M. Ruminant milk fat plasticity: Nutritional control of saturated, polyunsaturated, trans and conjugated fatty acids. Ann. Zootech. 2000, 49, 181-205. [CrossRef]

5. Lupitskyy, R.; Staff, C.; Satyavolu, J. Towards integrated biorefinery from dried distillers grains: Evaluation of feed application for co-products. Biomass Bioenergy 2015, 72, 251-255. [CrossRef]

6. Reis, C.E.R.; Rajendran, A.; Hu, B. New technologies in value addition to the thin stillage from corn-to-ethanol process. Rev. Environ. Sci. Biotechnol. 2017, 16, 175-206. [CrossRef]

7. West, T.P. Malic acid production from thin stillage by aspergillus species. Biotechnol. Lett. 2011, 33, $2463-2467$. [CrossRef] [PubMed]

8. Gonzalez, R.; Campbell, P.; Wong, M. Production of ethanol from thin stillage by metabolically engineered escherichia coli. Biotechnol. Lett. 2010, 32, 405-411. [CrossRef] [PubMed]

9. Rajendran, A.; Fox, T.; Hu, B. Nutrient recovery from ethanol co-products by a novel mycoalgae biofilm: Attached cultures of symbiotic fungi and algae. J. Chem. Technol. Biotechnol. 2017, 92, 1766-1776. [CrossRef]

10. Gutierrez-Correa, M.; Tengerdy, R.P. Production of cellulase on sugar cane bagasse by fungal mixed culture solid substrate fermentation. Biotechnol. Lett. 1997, 19, 665-667. [CrossRef]

11. Rajendran, A.; Hu, B. Mycoalgae biofilm: Development of a novel platform technology using algae and fungal cultures. Biotechnol. Biofuels 2016, 9, 112. [CrossRef] [PubMed]

12. Aidoo, K.E.; Hendry, R.; Wood, B.J.B. Estimation of fungal growth in a solid state fermentation system. Eur. J. Appl. Microbiol. Biotechnol. 1981, 12, 6-9. [CrossRef]

13. Reis, C.E.; Zhang, J.; Hu, B. Lipid accumulation by pelletized culture of Mucor circinelloides on corn stover hydrolysate. Appl. Biochem. Biotechnol. 2014, 174, 411-423. [CrossRef] [PubMed]

14. Spolaore, P.; Joannis-Cassan, C.; Duran, E.; Isambert, A. Commercial applications of microalgae. J. Biosci. Bioeng. 2006, 101, 87-96. [CrossRef] [PubMed]

15. Ratledge, C. Regulation of Lipid Accumulation in Oleaginous Micro-Organisms; Portland Press Limited: London, UK, 2002.

16. Xia, C.; Zhang, J.; Zhang, W.; Hu, B. A new cultivation method for microbial oil production: Cell pelletization and lipid accumulation by mucor circinelloides. Biotechnol. Biofuels 2011, 4, 15. [CrossRef] [PubMed]

(C) 2018 by the authors. Licensee MDPI, Basel, Switzerland. This article is an open access article distributed under the terms and conditions of the Creative Commons Attribution (CC BY) license (http:/ / creativecommons.org/licenses/by/4.0/). 